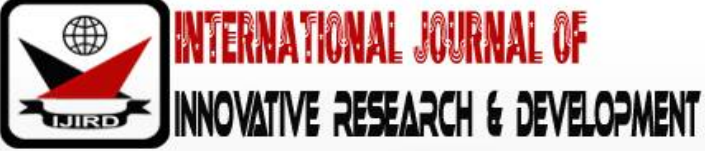

ISSN 2278 - 0211 (Online)

\section{Effects of the Environmental Pollutants on the Socio-economic Wellbeing of Households of Nairrobi County, Kenya}

\author{
Lucas E. Esekon \\ Student, Masinde Muliro University of Science and Technology (MMUST), Kenya \\ Dr. Ferdinard Nabiswa \\ Lecturer, Masinde Muliro University of Science and Technology (MMUST), Kenya \\ Dr. Edward Neyole \\ Lecturer, Masinde Muliro University of Science and Technology (MMUST), Kenya
}

\begin{abstract}
:
Environment is an essential part in human health which affects the quality of life. Health problems manifested from environmental pollution and mismanagement have changed it from a source of life to a cause of disease and death. In the developing world, population growth with urban crowding, the introduction of many environmental pollutants and toxic exposures, and the lack of clear policies to control pollution have accentuated the negative impact that these environmental factors can have as causative factors of disease in humans. The study sought to evaluate the effects of the water and air environmental pollutants on the socio-economic wellbeing of households in Mukuru informal settlements in Nairobi County. The study was underpinned by Ecological Theory of Change and Development. This study was carried out in the geographical area described as Mukuru Settlement of Nairobi City County. Mukuru informal settlement is situated on the southeast part of Nairobi County, along the Ngong River, exactly between the industrial area and the affluent residential of South B. The target population of this study comprised households' heads, public health officers, and community leaders as key informants. The study found that main effects of water and air pollutants in the area were the constant disease outbreaks such as cholera which was occasioned by water pollution.
\end{abstract}

Keywords: Pollution, human health, toxic waste, water pollution, air pollution

\section{Introduction}

Pollutants may cause primary damage, with direct identifiable impact on the environment, or secondary damage in the form of minor perturbations in the delicate balance of the biological food web that are detectable only over long time periods. According to Carter, (2015) the most common types of pollutants in an urban setting which is the focus of this study are the air pollutants, water pollutants and noise pollutants. Air pollutants include carbon monoxide, ozone, nitrogen oxides, lead and sulphur dioxide which are introduced into the atmosphere through emissions from transportation, industrial processes and burning of solid wastes (Mishra, 2013). Water pollutants on ther other hand include, fecal discharges, bacterial pollution, phosphorous, nitrates e.t.c. which get in to the water supply through sewage treatments, industrial waste, illegal dumping of solid waste, septic systems.

According to Levasseur and Marcoux (2015) polluted water is the world's largest health risk, and continues to threaten both quality of life and public health. Associated with this are health service costs, loss life expectancy, and emergency health costs associated with major pollution events. Water pollution has drastically risen across three continents, placing hundreds of millions of people at risk of contracting life-threatening diseases like cholera and typhoid. The worrying rise in the pollution of surface waters in Asia, Africa and Latin America also threatens to damage vital sources of food and harm the continents' economies (Budds \& McGranahan, 2013).

By making access to quality water even more difficult, water pollution also threatens to breed further inequality, hitting the most vulnerable; women, children and the poor the hardest. The increasing amount of wastewater being dumped into our surface waters is deeply troubling (Kan, 2013). Access to quality water is essential for human health and human development. Population growth, increased economic activity, the expansion and intensification of agriculture, and an increase in the amount of untreated sewage discharged into rivers and lakes are the main reasons behind the troubling rise in surface water pollution in Asia, Africa and Latin America (Budds \& McGranahan, 2013)

Numerous studies have found associations between air pollution and acute lower respiratory infection (Smith, 2010; Ezzati \& Kammen, 2012), chronic obstructive pulmonary disease (Bruce, Perez-Padilla, \& Albalak, 2010) and lung cancer in the case of coal smoke. There is emerging evidence that air pollution increases the risk of other child and adult 
health problems, including low birth-weight, perinatal mortality, asthma, otitis media (or middle ear infection), tuberculosis, nasopharyngeal cancer, cataracts, blindness, and cardiovascular disease (WHO, 2018). In fact, the World Health Organization estimates that air pollution is responsible for $2.7 \%$ of the loss of disability adjusted life years (DALYs) worldwide and 3.7\% in high-mortality developing countries. More recently, Zhang and Smith, (2017) undertook a very thorough meta-analysis of 200 publications regarding air pollution in China. They showed that most of the studies find a strong correlation between air pollution and negative health outcomes: lung function reductions, immune system impairment, lung cancer, etc.

\section{Theoretical Framework}

The study was underpinned by Ecological Theory of Change and Development. The theory is associated with the works of Wilkinson and Boulding (1973). The theory is concerned with issues of change and development in contemporary societies, especially as they relate to environmental changes and/or ecologically related trends of population growth and the need to devise and sort out techniques of tackling development problems. The theory states that, as the population of a society increases in size, individual members of the society exert more pressure on scarce available resources such as land and other natural endowments for survival (Ocheri, 2013). They directly or indirectly carryout socioeconomic activities that pollute the environment/ society, and further cause harm (degradation) to the environment/ society. The socio-economic activities, according to these theorists include subsistence agricultural activities of people in agrarian societies and the commercial and industrial activities of people in urban industrialized societies.

The theory further argue that development is needed when a society out grow its resource base and productive system. The theory therefore posits that as the established economic system of a given environment/ society is proved inadequate and productive system becomes more problematic, societies are therefore driven to change their methods (Ocheri, 2013). For instance, as the population of a society outgrows the available resources, especially in agrarian societies, people are forced to migrate to urban centres/ cities in search of job opportunities. Some sell their labour, whereas some engage in several other commercial and agricultural investments such as livestock; some still carry out some technical and entrepreneurial businesses all for survival.

The urban and city dwellers establish and carryout industrial activities that equally pollute the society. Wilkinson and Boulding, (1973) conclude that these activities directly and/ or indirectly pollute the environment with its attendant consequences on biodiversity. The theory was therefore important for this study in explaining the continued existence of the informal settlement dwellers in the informal settlements despite the challenges therein, how they, and others, carryout socioeconomic activities that pollute the environment they live in and establish how the polluted environment consequently affect their socio-economic well-being.

\section{Research Methodology}

The study employed descriptive survey research design because it involves measuring different variables in the population of interest at a single point in time. This study was carried out in the geographical area described as Mukuru Settlement of Nairobi City County. Mukuru informal settlement is situated on the southeast part of Nairobi County, along the Ngong River, exactly between the industrial area and the affluent residential of South B. The target population of this study comprised households' heads, public health officers, and community leaders as key informants. Additionally, officers from the National disaster management unit in the ministry of interior were interviewed. The study employed simple random sampling technique to sample 352 households' heads to participate in the study while purposive sampling was used to select 4 public health officers 10 community leaders and 5 National Disaster Management Unit officers to participate in the interview. Primary data was collected through questionnaires, interviews, observations and focus group discussions. Secondary data was also utilised during the study.

\section{Findings}

\subsection{Relationship between the Environmental Pollutants and Household Socio-Economic Well-Being}

The key informants (community leaders) were requested to state the relationship between the environmental pollutants and household socio-economic well-being in the Mukuru settlements. They stated that the awful smells around the area emanating from the uncollected solid wastes as well as open sewerage systems kept away the customers who would come to buy food items from their stalls. They stated that this affected the small businesses which were some of the residents' only source of livelihood and which therefore affected their ability to provide for their families.

The public health officers also indicated that main effects of environmental pollutants in the area were the constant disease outbreaks such as cholera which was occasioned by water pollution. They also stated that diseases such as Malaria was also caused by the inadequate drainage systems as well as uncollected garbage in the area.

\subsection{Effect of Water Pollution}

\subsubsection{Water Pollution Effect on Socio-economic Wellbeing}

The study sought to find out whether water pollution affected the resident's socio-economic wellbeing. The findings were as illustrated in Figure 1. 


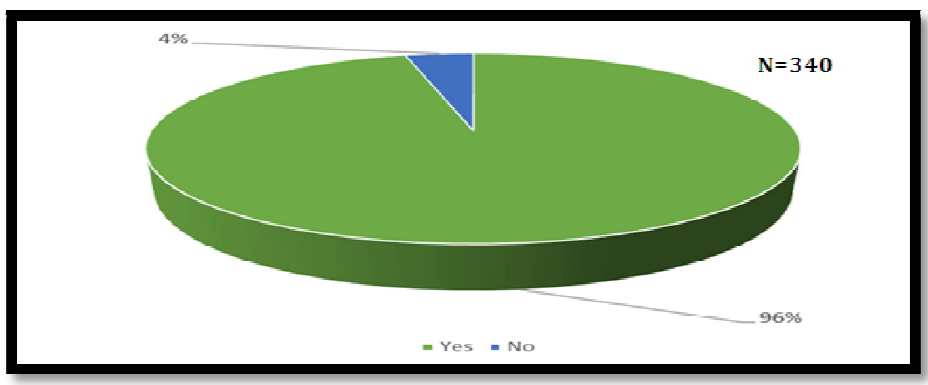

Figure 1: Water Pollution effect on Socio-economic Wellbeing Source: Field Data (2019)

As indicated in the figure, majority (96\%) of the respondents stated that water pollution affected the resident's socio-economic wellbeing while the rest (4\%) stated otherwise. This demonstrates that indeed water pollution affected the resident's socio-economic wellbeing.

The key informants (community leaders) were requested to state how water pollution affected the socioeconomic well-being of households in the Mukuru informal settlements and stated that lack of clean water, occasioned by the pollution, hurt the small businesses in the area that were source of livelihoods for most of the residents, both the owners and those employed in them. They also stated that the water pollution occasionally resulted in disease outbreaks such as cholera which whose treatment ate into the small income the residents earned. This was in line with Levasseur and Marcoux, (2015) who posists that the largets world health risk is polluted water which threatens the quality of life of human beings.

The focus group discussions that were made up of randomly selected household heads also revealed that water pollution affected the residents of Mukuru informal settlements. One participant stated,

"There have been disease outbreaks such as the recent cholera outbreak which was caused by contaminated water." Another participant stated, "Most of us here are casual labourers or small business owners which means whenever we don't go to work due to illnesses caused by water contamination, our families suffer because they don't have money to buy food."

This is in line with Levasseur and Marcoux, (2015) who posited that when people get sick due to pollution, their income and that of the businesses they work for becomes lower than it would be in the absence of pollution.

\subsubsection{Extent that Water Pollution Affect the Socio-economic Wellbeing}

The study also sought to establish the extent to which the water pollution affected the residents' socio-economic wellbeing. The findings were as presented in Table 1. As illustrated, majority (79\%) of the respondents indicated that water pollution affected the residents' socio-economic wellbeing to a great extent, $14 \%$ to a very great extent, while $4 \%$ and $3 \%$ stated that water pollution affected the residents' socio-economic wellbeing to a very low extent and to a moderate extent respectively. This shows that the residents' socio-economic wellbeing was affected by water pollution to a great extent. This was in line with Levasseur and Marcoux, (2015) who stated that the effect of pollution on human health impacted on the socio-economic wellbeing of individuals in that sick or dead people can not contribute to the economy.

\begin{tabular}{|c|c|}
\hline Extent & Percentage (\%) ) \\
\hline To a very low extent & 4 \\
\hline To a low extent & 0 \\
\hline To a moderate extent & 3 \\
\hline To a great extent & 79 \\
\hline To a very great extent & 14 \\
\hline Total & 100 \\
\hline
\end{tabular}

Table 1: Extent That Water Pollution Affects the

Socio-Economic Wellbeing

Source: Field Data (2019)

\subsubsection{Respondents' Level Of Agreement On Effects Of Water Pollution}

The respondents were also requested to state their level of agreement to statements relating to the relationship between the water pollution and household socio-economic wellbeing. The findings were as illustrated in table 4.2. As illustrated, majority of the respondents strongly agreed that improperly treated sewerage and uncollected garbage had contributed to a vicious cycle of water pollution as shown by a mean score of 4.66. Additionally, the respondents strongly agreed that contaminated drinking water causes waterborne diseases which eats into the households' livelihoods and that water pollution had led to increase in mortality of household heads affecting the socio-economic wellbeing as evidenced by mean scores of 4.62 and 4.60 respectively. The respondents also agreed that industrial waste from adjacent industries had led to water borne diseases and that human health impacts of water pollution affected income and its use as shown by 
mean scores of 4.48 and 4.32 respectively. The respondents further agreed that water pollution in the area had led to increase in the economic inequality gap as evidenced by a mean score of 4.29.

\begin{tabular}{|c|c|c|}
\hline Statements & Mean & Standard Dev \\
\hline Human health impacts of water pollution affect income and its use & 4.32 & 0.674 \\
\hline $\begin{array}{c}\text { Contaminated drinking water causes waterborne diseases which } \\
\text { eats into the households' livelihoods }\end{array}$ & 4.62 & 0.289 \\
\hline $\begin{array}{c}\text { Water pollution has led to increase in mortality of household heads } \\
\text { affecting the socio-economic wellbeing }\end{array}$ & 4.60 & 0.397 \\
\hline $\begin{array}{c}\text { Water pollution in this area has led to increase in the economic } \\
\text { inequality gap }\end{array}$ & 4.29 & 0.904 \\
\hline $\begin{array}{c}\text { Improperly treated sewerage and uncollected garbage have } \\
\text { contributed to a vicious cycle of water pollution }\end{array}$ & 4.66 & 0.314 \\
\hline $\begin{array}{c}\text { Industrial waste from adjacent industries has led to water borne } \\
\text { diseases }\end{array}$ & 4.48 & 0.521 \\
\hline
\end{tabular}

Table 2: Respondents' Level of Agreement on Effects of Water Pollution Source: Field Data (2019)

\subsection{Effect of Air Pollution}

\subsubsection{Air Pollution Effect on Socio-economic Wellbeing}

The study also sought to find out whether air pollution affected the resident's socio-economic wellbeing. Figure 2 below shows the findings.

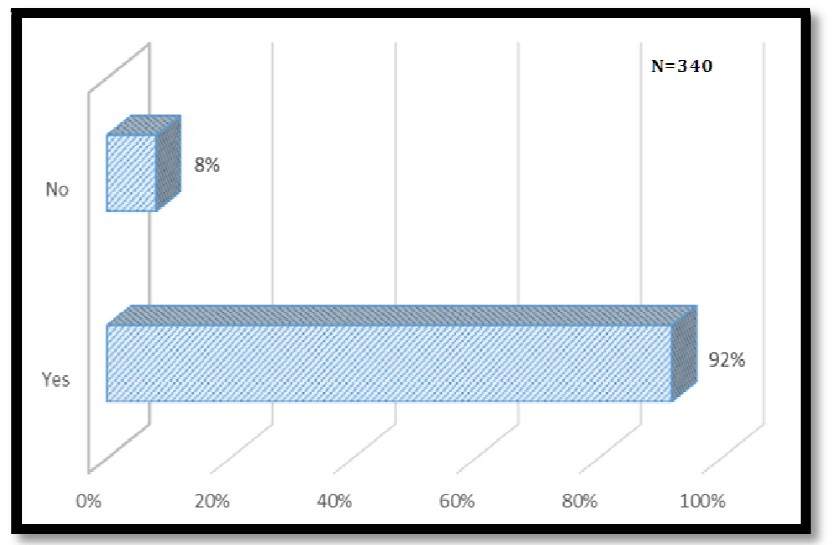

Figure 2: Air Pollution Effect on Socio-Economic Wellbeing Source: Field Data (2019)

Majority (92\%) of the respondents stated that air pollution affected the resident's socio-economic wellbeing while $8 \%$ stated the contrary. This shows that indeed air pollution affected the resident's socio-economic wellbeing.

The community leaders were requested to state how air pollution affected the socio-economic well-being of households in the Mukuru informal settlements. They stated that air pollution emanating from the motor vehicles, the bad smells from the uncollected solid waste and the industries in the business areas, kept potential customers away. This hurt the income of the small business owners which consequently hurt those employed in the businesses. Additionally, the community leaders stated that the air pollution affected the nearby schools as pupils' health was affected thereby affecting their grades. This concurred with Mbinda and Kammen, (2014) who stated that for rural dwellers as well as informal settlement dwellers, air pollution remained a health threat globally.

The focus group discussions revealed that air pollution affected the residents' health especially the children. One participant said,

"...some of our children miss their classes as they seek medical check-up for their eyes which are affected by use of paraffin lamps and burning of waste..."

This concurs with Mishra, (2013) who stated that air pollution in cities caused shorter lifespans for those dwelling in the cities. The burning of waste was also ascertained during observation as illustrated in Figure 3. 


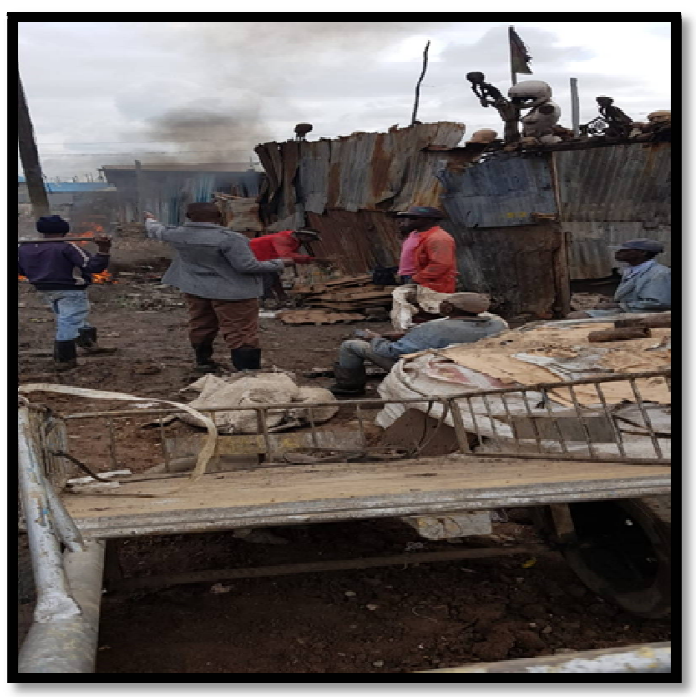

Figure 3: Air Pollution through Burning of waste Source: Author (2019)

Plate 5.1 illustartes the burning of waste by the residents and has pictured the researcher engaging them on the reasons for burning of the waste to which they stated that they didn't have an option as there were no garbage collection points available for them.

\subsubsection{Extent that Air Pollution affect Socio-economic Wellbeing}

The study also sought to establish the extent to which the air pollution affected the residents' socio-economic wellbeing. The findings were as presented in table 4.3.

\begin{tabular}{|c|c|}
\hline Extent & Percentage (\%) \\
\hline To a very low extent & 2 \\
\hline To a low extent & 1 \\
\hline To a moderate extent & 4 \\
\hline To a great extent & 82 \\
\hline To a very great extent & 11 \\
\hline Total & 100 \\
\hline
\end{tabular}

Table 3: Extent That Air Pollution Affect the Socio-economic Wellbeing Source: Field Data (2019)

The findings indicate that majority (82\%) of the respondents agreed that air pollution affected the residents' socio-economic wellbeing to a great extent, $11 \%$ to a very great extent, $4 \%$ to a moderate extent, $2 \%$ to a very low extent and $1 \%$ to a low extent. This illustrates that air pollution affected the residents' socio-economic wellbeing to a great extent. This concurs with Zhang and Smith (2017), who found a strong relationship between air pollution and negative health outcomes which ate into the income of the victims.

\subsubsection{Respondents' Level of Agreement on Effects of Air Pollution}

The study also sought to establish the respondents' level of agreement on statements relating to the relationship between air pollution and household socio-economic wellbeing. The findings were as illustrated in Table 4.

\begin{tabular}{|c|c|c|}
\hline Statements & Mean & Standard Dev \\
\hline $\begin{array}{c}\text { Air pollution by vehicles and industries has led to an increase in infant } \\
\text { mortality rates }\end{array}$ & 4.18 & 0.724 \\
\hline $\begin{array}{c}\text { Air pollution by the industries have also indirectly affected our rain water } \\
\text { source through acid rain }\end{array}$ & 4.55 & 0.389 \\
\hline $\begin{array}{l}\text { Our iron sheet roofs have all rusted and started to leak due to air } \\
\text { pollution }\end{array}$ & 4.61 & 0.385 \\
\hline Air pollution affects the school attendance and productivity of children & 4.02 & 0.984 \\
\hline $\begin{array}{c}\text { Household air pollution is dangerous and is easily ignored until health } \\
\text { effects are felt }\end{array}$ & 4.68 & 0.320 \\
\hline $\begin{array}{l}\text { Air pollution causes terminal illnesses which deter the household heads } \\
\text { from being economically active for the families }\end{array}$ & 4.52 & 0.480 \\
\hline
\end{tabular}

Table 4: Respondents' Level of Agreement on Effects of Air Pollution

Source: Field Data (2019) 
As per the findings shown on the table, the respondents strongly agreed that household air pollution was dangerous and was easily ignored until health effects were felt as shown by a mean score of 4.68. The respondents also strongly agreed that their iron sheet roofs had all rusted and started to leak due to air pollution and that air pollution by the industries had also indirectly affected their rain water source through acid rain as shown by mean scores of 4.61 and 4.55 respectively. Observation also revealed that the rusted iron sheets had indeed rusted as illustrated in plate 5.2.

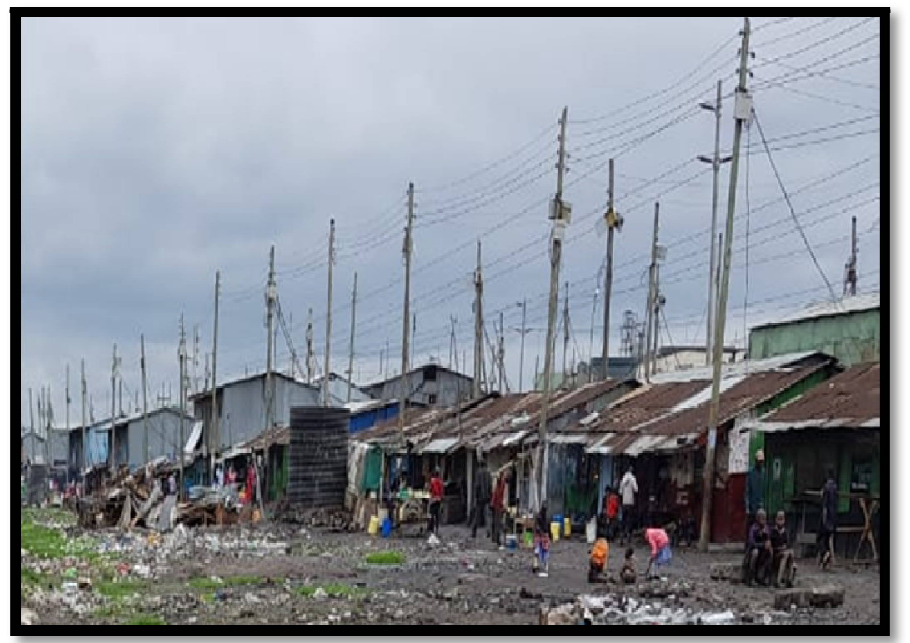

Figure 4: Image Showing Rusted Iron Sheets In Mukuru

Informal Settlements

Source: Author (2019)

Additionally, the respondents strongly agreed that air pollution caused terminal illnesses which deterred the household heads from being economically active for the families as evidenced by a mean score of 4.52 . This was in line with Smith, (2010) who posits that sick individuals can not involve themselves in strenuous jobs. The respondents also agreed that air pollution by vehicles and industries had led to an increase in infant mortality rates and that air pollution affected the school attendance and productivity of children as illustrated by mean scores of 4.18 and 4.02 respectively. This was in line with Jayachandran, (2016) who found that air pollution resulted in increased infant mortality rates.

\subsubsection{Other effects of Environmental Pollutants}

The study also sought to establish how else the environmental pollutants had affected the residents' household socio-economic wellbeing. The respondents stated that the residents suffered from the fumes from the industries and their fuel use which caused severe coughs and difficulty in breathing. Most of the residents stated that the air pollution caused asthma for some of the residents with most of them being potential victims of the same. This concurred with the WHO (2018) which found that air pollution increased risk of developing respiratory health problems such as asthma, nasopharyngeal cancer, acute lower respiratory infection and other complications. The air pollution also caused irritation of the nose and eyes as well as irritation of the throat which hindered the children from concentrating in their studies.

\subsection{Households' Socio-economic Wellbeing}

\subsubsection{Respondents' Level of Agreement on Their Socio-economic Wellbeing}

The study also sought to establish the respondents' level of agreement on statements relating to their socioeconomic wellbeing. The findings were as illustrated in Table 5.

As indicated, most of the respondents strongly agreed that they didn't have enough money to use in the house and remain with some to save as evidenced by a mean score of 4.68. Additionally, the respondents strongly agreed that their family members were constantly experiencing health challenges as shown by a mean score of 4.63 . The respondents also strongly agreed that most of the household heads were kept out of work by constant health problems and that the families in the area had difficulties in accessing food and water as illustrated by mean scores of 4.57 and 4.54 respectively. The respondents also agreed that the education of their children was affected by the constant health issues and that their living conditions has gradually deteriorated as demonstrated by mean scores of 4.41 and 4.39 respectively. 


\begin{tabular}{|c|c|c|}
\hline Statements & Mean & Standard Dev \\
\hline $\begin{array}{c}\text { Our living conditions has gradually deteriorated } \\
\text { The education of our children is affected by the constant health } \\
\text { issues }\end{array}$ & 4.39 & 0.31 \\
\hline $\begin{array}{c}\text { Our family members are constantly experiencing health } \\
\text { challenges }\end{array}$ & 4.63 & 0.465 \\
\hline The families here have difficulties in accessing food and water & 4.54 & 0.289 \\
\hline We don't have enough money to use in the house and save & 4.68 & 0.386 \\
\hline $\begin{array}{c}\text { Most of the household heads are kept out of work by constant } \\
\text { health problems }\end{array}$ & 4.57 & 0.374 \\
\hline
\end{tabular}

Table 5: Respondents' Level of Agreement on Their Socio-Economic Wellbeing Source: Author (2019)

\subsubsection{Extent of Environmental Pollution's Effect on Socio-Economic Wellbeing}

The researcher also requested the respondents to state the extent to which their socio-economic wellbeing was affected by environmental pollution. The findings were as illustrated in Figure 5. As shown, most (54\%) of the respondents stated that their socio-economic wellbeing was affected by environmental pollution to a very great extent, $42 \%$ to a great extent, $3 \%$ to a moderate extent and $1 \%$ to a low extent. This signifies that the residents' socio-economic wellbeing was affected by environmental pollution to a very great extent.

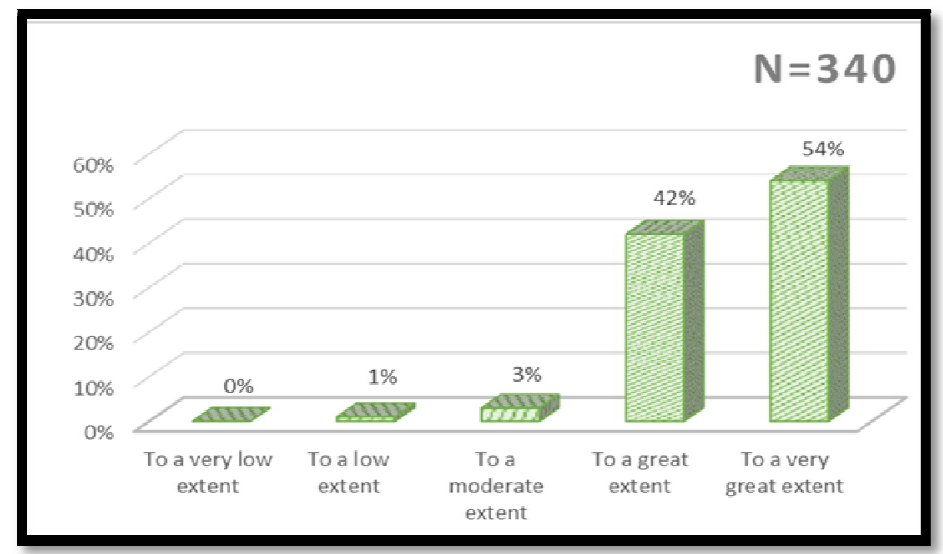

Figure 5: Extent of Environmental Pollution's Effect on

Socio-Economic Wellbeing

Source: Author (2019)

\subsection{Inferential Analysis}

To compute the correlation between dependent variable and the independent variables the study conducted inferential analysis which involved Karl Pearson's coefficient of correlation, regression analysis, model summary and a multiple regression analysis.

\subsubsection{Correlation Analysis}

According to the findings as illustrated in Table 6, it was clear that there was a negative correlation between the households' socio-economic wellbeing and air pollution as shown by a correlation figure of 0.521 , it was also clear that there was a negative correlation between their socio-economic wellbeing and water pollution with a correlation figure of 0.618. This shows that there was a negative correlation between the households' socio-economic wellbeing and air pollution as well as water pollution. This notwithstanding, all the variables were significant as their P-values were less than 0.05 . 


\begin{tabular}{|c|c|c|c|c|}
\hline \multicolumn{2}{|c|}{} & $\begin{array}{c}\text { Socio-economic } \\
\text { Wellbeing }\end{array}$ & $\begin{array}{c}\text { Air } \\
\text { Pollution }\end{array}$ & Water Pollution \\
\hline $\begin{array}{c}\text { Socio-economic } \\
\text { wellbeing }\end{array}$ & $\begin{array}{c}\text { Pearson } \\
\text { Correlation } \\
\text { Sig. (2-tailed) }\end{array}$ & 1 & & \\
\hline Air pollution & $\begin{array}{c}\text { Pearson } \\
\text { Correlation }\end{array}$ & -0.5210 & 1 & \\
\hline & Sig. (2-tailed) & .0032 & & \\
\hline Water pollution & $\begin{array}{c}\text { Pearson } \\
\text { Correlation }\end{array}$ & -0.6180 & .3421 & \\
\hline & Sig. (2-tailed) & .0021 & .0014 & \\
\hline
\end{tabular}

Table 6: Coefficient of Correlation

Source: Author (2019)

\subsubsection{Coefficient of Determination}

The coefficient of determination was carried out to measure how well the statistical model was likely to predict future outcomes. The coefficient of determination, $\mathrm{r}^{2}$ is the square of the sample correlation coefficient between outcomes and predicted values. As such it explains the effect of the two independent variables (water pollution and air pollution) on the dependent variable.

As summarized on Table 4.7, of the two independent variables that were studied, only $55.1 \%$ of the Socioeconomic wellbeing was represented by the adjusted $\mathrm{R}^{2}$. This therefore means that other variables not studied in this research affect $44.9 \%$ of Socio-economic wellbeing. Therefore, further research should be conducted to investigate the other (44.9\%) variables that affect households' socio-economic wellbeing.

\begin{tabular}{|c|c|c|c|c|}
\hline Model & $\mathbf{R}$ & $\begin{array}{c}\text { R } \\
\text { Square }\end{array}$ & $\begin{array}{c}\text { Adjusted R } \\
\text { Square }\end{array}$ & $\begin{array}{c}\text { Std. Error of the } \\
\text { Estimate }\end{array}$ \\
\hline 1 & 0.742 & 0.551 & 0.641 & 0.0438 \\
\hline
\end{tabular}

Table 7: Model Summary

Source: Author (2019)

\subsubsection{Multiple Regression}

The study further conducted a multiple regression analysis so as to identify the relationship of the two independent variables and the socio-economic wellbeing. The main purpose of multiple regressions is to learn more about the relationship between several independent or predictor variables and a dependent or criterion variable. The researcher applied the statistical package for social sciences (SPSS) to code, enter and compute the measurements of the multiple regressions for the study. As per the SPSS generated table 5.8, the equation,

$\left(\mathrm{Y}=\beta_{0}+\beta_{1} \mathrm{X}_{1}+\beta_{2} \mathrm{X}_{2}+\varepsilon\right)$ becomes:

$\mathrm{Y}=1.279+\left(-0.508 \mathrm{X}_{1}\right)+\left(-0.613 \mathrm{X}_{2}\right)+\varepsilon$

The regression equation above has established that taking all factors into account (air pollution and water pollution) constant at zero, the socio-economic wellbeing will be 1.279. The findings presented on Table 8 also show that taking the other independent variable at zero, a unit increase in air pollution will lead to a 0.525 decrease in the socioeconomic wellbeing; a unit increase in water pollution will lead to a 0.613 decrease in the socio-economic wellbeing. This infers that water pollution affect the socio-economic wellbeing to a great extent, followed by air pollution.

\begin{tabular}{|c|c|c|c|c|c|}
\hline Model & $\begin{array}{c}\text { Unstandardized } \\
\text { Coefficients }\end{array}$ & $\begin{array}{c}\text { Standardized } \\
\text { Coefficients }\end{array}$ & & \multirow{2}{*}{} & \\
\cline { 2 - 3 } \cline { 3 - 4 } & $\mathrm{B}$ & Std. Error & Beta & & Sig. \\
\hline (Constant) & 1.279 & 1.316 & & 0.972 & 0.0357 \\
\hline Air pollution & -0.525 & 0.156 & 0.21 & 3.365 & 0.0249 \\
\hline Water pollution & -0.613 & 0.322 & 0.067 & 1.904 & 0.0202 \\
\hline
\end{tabular}

Table 8: Regression Coefficients

\section{Conclusion}

The study concluded that the main effects of water and air pollutants in the area were the constant disease outbreaks such as cholera which was occasioned by water pollution. Lack of clean water, occasioned by the pollution, hurt the small businesses in the area thereby affecting their economic livelihoods. Air pollution caused terminal illnesses which deterred the household heads from being economically active for the families.

\section{Recommendation}

The study recommends that the community should be actively engaged in the protection of their environment by first responsibly disposing the solid waste in the right manner. They should designate a single location of disposing the waste then lobby the county government to collect the solid waste. 


\section{References}

i. Bruce, N., Perez-Padilla, R., \& Albalak, R. (2010). Indoor Air Pollution in Developing Countries: A Major Environmental and Public Health Challenge. Bulletin of the World Health Organization, 78 (9): 1078-92.

ii. Budds, J., \& McGranahan, G. (2013). Are the debates on water privatization missing the point? Experiences from Africa, Asia and Latin America. Environment and Urbanization, Vol 15, No 2, pages 87-113.

iii. Carter, F. W. (2015). Pollution Problems in Post-War Czechoslovakia. Transactions of the Institute of British Geographers, 10(1), pp. 17-44.

iv. Ezzati, M., \& Kammen, D. M. (2012). Evaluating the health benefits of transitions in household energy technology in Kenya. Energy Policy, 30:815-26.

v. Jayachandran, S. (2016). Air Quality and Early Life Mortality: Evidence from Indonesia's Wildfires. mimeo, 41 (11), 886-887.

vi. Kan, H. (2013). Environment and Health in China: Challenges and Opportunities . Environmental Health Perspectives, 117(12), pp. A530-A531.

vii. Khan, S. I. (2014). Dumping of Solid Waste: A Threat to Environment, the Dawn. Central European Journal of Public Health. 2(4), 214-226.

viii. Levasseur, J., \& Marcoux, J. M. (2015). Bad water: "Third World" conditions on First Nations in Canada. The Lancet, 380(9859): 2224-60.

ix. Mbinda, B., M., E., \& Kammen, D. (2014). Comparison of emissions and residential exposure from traditional and improved biofuel stoves in rural Kenya. Environmental Science and Technology, 84:578-83.

x. Mishra, V. (2013). Health Effects of Air Pollution, Background paper for Population-Environment Research Network (PERN). Cyberseminar, 1-15.

xi. Ocheri, M. I. (2013). Environmental Health Hazards and national Survival and Stability: A need for Education . Benue State University Journal of Education (BSUJE), Vol 4. No. 2. 67-174. Smith, K. R. (2010). National Burden of Disease in India from Indoor Air Pollution. Proceedings of the National Academy of Sciences of the United States of America, 97 (24): 13286-13293.

xii. WHO. (2018). Global Health Observatory (GHO) data . Retrieved from World Health Organization: http:/ / www.who.int/ gho/ urban health/ en/

xiii. Wilkinson, R. G., \& Boulding, K. E. (1973). Poverty and Progress: an ecological perspective on economic development. New York - Washington: Preager Preager.

xiv. Zhang, J., \& Smith, K. R. (2017). Household Air Pollution from Coal and Biomass Fuels in China: Measurements, Health Impacts, and Interventions. . Environmental Health Perspective, 115:848-855. 